\title{
Critical success factors for ERP implementation in SMEs
}

\author{
Prodromos Chatzoglou \\ Democritus University of Thrace, \\ Vasillisis Sofias 12, 67100, Xanthi, Greece \\ Email: pchatzog@pme.duth.gr \\ Leonidas Fragidis \\ Democritus University of Thrace, \\ Vasillisis Sofias 12, 67100, Xanthi, Greece \\ Email:1frangid@pme.duth.gr
}

\author{
Dimitrios Chatzoudes \\ Democritus University of Thrace, \\ Vasillisis Sofias 12, 67100, Xanthi, Greece \\ Email: dchatzoudes@yahoo.gr \\ Symeon Symeonidis \\ Democritus University of Thrace, \\ Vasillisis Sofias 12, 67100, Xanthi, Greece \\ Email: ssymeoni@ee.duth.gr
}

\begin{abstract}
The highly competitive global environment of the last few decades has urged companies to rely on Information Systems (IS) in order to improve customer service, reduce costs and increase productivity. In that direction, Enterprise Resource Planning (ERP) systems are being used as significant strategic tools that provide competitive advantages and lead to operational excellence. Despite that, ERP implementation projects are complicated, costly and include high failure risks. The present study aims (a) to develop and (b) empirically test a conceptual framework that investigates the factors affecting ERP system effective implementation in Small and Medium Enterprises (SMEs). The examination of the conceptual framework was made with the use of a newly-developed structured questionnaire that was distributed to a group of Greek SMEs. After the completion of the research period, 159 usable questionnaires were returned. The reliability and the validity of the questionnaires were thoroughly examined, while research hypotheses were tested using the "Structural Equation Modeling" (SEM) technique. Results offer interesting empirical observations and managerial implications.
\end{abstract}

\section{INTRODUCTION}

$\mathrm{T}$ HE business world has been hugely transformed during the last few decades [1]. Globalisation, increasing competition, constant change in the external environment, and private sector growth are among the most significant changes in the global business environment [2]. These transformations have urged most companies to adapt in order to survive [1] [3] [4].

More specifically, organisations aim at maintaining or improving the level of their competitiveness by using Information Systems (IS) in order to reduce costs, increase customer satisfaction, and improve business processes [5]. According to various authors [3] [6] [7], this drive for achieving higher levels of productivity, effectiveness, and performance is urging organisations to adopt Enterprise Resource Planning (ERP) systems. Tsai, Li, Lee and Tung [4] argue that, since their introduction in the early 1990s, ERP systems have become the centre of modern business.

ERP systems are Information Systems (IS) that facilitate the integration of business processes across functional units, using a common database and shared information [4] [6] [8].

This work was not supported by any organization.
According to Garg and Garg [8], this "enables the decisionmaking process to be timely, consistent and reliable across organizational units and geographical locations" (p. 424).

ERP implementation has various benefits throughout the organisation: elimination of redundant information, drastic declines in inventory, reduction of production cost, better understanding of the changing customer needs, more efficient management of the extended network of suppliers and customers, increased productivity, improved response time, and decreased production cycle [5] [8] [9] [10] [11]. Considering these benefits, it is not surprising that ERP systems are being treated as a major development in the world of business, and have been accepted as a standard business software over the last fifteen years [8] [12].

However, ERP implementation requires considerable financial resources, while the whole implementation project is considered complex, lengthy, and quite challenging [9] [13]. As a result, the success rate of such projects is considered to be quite disappointing [14] [15] [16]. More specifically, Samuel and Kumar [17], argue that the success rate is, only, around $50 \%$, while approximately $90 \%$ of ERP implementation projects are late, or over budget. On the same vein, Umble and Umble [18] reported failure rates between $50 \%$ and $75 \%$. Therefore, additional empirical studies are necessary in order to assist companies in increasing the success rates of ERP implementation projects.

Under that context, the aim of the present study is twofold: (a) develop an original conceptual framework (research model) examining the impact of various research factors on ERP implementation success, (b) empirically test that framework, using data from Small and Medium Enterprises (SMEs) located in Greece (empirical research).

(a) The development of the conceptual framework was based on two methodological steps: firstly, a review of the literature identified the factors that were used by previous studies as antecedents of ERP implementation success; secondly, a panel of experts was used in order to discuss these factors and provide a list of the most significant ones. That approach was selected due to the significant number of factors that have been proposed in the relevant literature. More specifically, the members of the research team used the opinions of experienced practitioners as a criterion for selecting a specific set of factors from the extensive list that 
was provided from the literature review analysis. It is strongly argued that randomly selecting the research factors of the proposed conceptual framework would have resulted in the limited reliability of the present research.

(b) The empirical examination of the conceptual framework (that was crystallised after the literature review analysis and the completion of the qualitative research) was conducted on a sample of Greek SMEs. More specifically, a newly-developed structured questionnaire was used in order to collect the appropriate primary data. The questionnaire was distributed to 421 companies, while 159 usable questionnaires were, finally, returned. Advanced statistical techniques (EFA, CFA) were used in order to enhance the validity and reliability of the results, while research hypotheses were tested using the "Structural Equation Modeling" (SEM) technique.

The present study makes an effort to point out areas that companies should emphasize in order to successfully adopt ERP systems and, therefore, harvest their potential benefits. Its contribution lies in this enhanced approach. In synopsis, the study contributes in the following areas:

- It focuses on Small and Medium enterprises (SMEs), an approach that has found limited empirical investigation in the international literature. The literature review analysis underlined that the contemporary research mostly examines the implementation of ERP systems in large organizations.

- It examines the antecedents of ERP implementation success in SMEs of a European country. The literature review analysis that was conducted failed to recognise enough similar studies.

- It uses a qualitative research in order to recognise the most important antecedents of ERP implementation success and, then, develops a conceptual framework based on these factors. According to the best of the researchers' knowledge, such an approach is unique in the relevant literature. Moreover, it is significant, since previous studies used factors that were randomly selected from the literature, without a solid empirical basis [8] [19] [20] [21].

- It can be perceived as a reference point for future studies, since it offers a critique concerning the multitude of ERP implementation antecedents that have been examined in the international literature.

- Its results may be generalized in other developed countries with similar characteristics, and produce valuable managerial lessons for practitioners in these countries.

The following section includes a review of the relevant literature, while section three presents the conceptual framework of the study. The fourth section includes the research methodology. Results and conclusions are discussed in sections 5 and 6 respectively.

\section{II.LITERATURE REVIEW}

\section{A. Critical success factors}

Critical Success Factors (CSFs) have been introduced during the 1960s, as a concept that would assist companies to achieve their goals and enhance their overall competitiveness [22] [23] [24]. According to Ram and
Corkindale [22], CSFs constitute a systematic way of identifying key business areas that require constant management attention. On the same vein, Rockart [23] argues that the results obtained in these critical areas, if satisfactory, are able to significantly enhance organisational performance. In plain words, CSFs assist managers to directly affect a specific outcome, by proactively taking necessary actions in certain areas [25].

Not surprisingly, the concept of CSFs gained wide recognition in the Information Systems domain and, consequently, in the context of ERP systems [6]. Since high failure rates of ERP implementation projects have been observed by numerous studies [14] [15], many scientists have attempted to investigate the factors that may enhance the whole implementation process. According to Ram, Corkindale and $\mathrm{Wu}$ [19], a large number of CSFs have been identified throughout the international literature.

Indeed, the literature review analysis that was conducted revealed that the relevant literature includes numerous studies that have, mostly, been published during the last 15 years [24]. Among these studies, some are theoretical [26], some others are empirical [8] [9] [27], while just a few have adopted the case-study approach [28].

According to Saade and Nijher [24], despite the growth in the investigation of CSFs regarding ERP implementation, there is a long way before the empirical contribution can be considered to be substantial. Moreover, most of the empirical studies that have been conducted [8] [9] [21], incorporated a limited number of critical factors in their analysis, failing to draw a more complete picture of the phenomenon. Finally, despite the wide range of CSFs proposed in the literature, many organisations continue to experience failures and difficulties in implementing ERP systems [19], thus, calling for additional research.

More significantly, according to Ram and Corkindale [22], there is a lack of an established process for the identification of CSFs. Various authors use subjective criteria in order to select the critical factors utilised in their studies, something that results in a lack of objective approaches. The present study heals that gap in the relevant literature, by developing a conceptual framework that was crystallised after a coherent two-step approach (literature review analysis and consultation with experienced practitioners / focus-group methodology).

\section{B. Previous studies}

Numerous empirical studies have investigated the critical success factors for ERP system implementation. The present study conducted an extensive review of the relevant literature, in an effort to grasp a spherical view of the subject and, therefore, better define its scope. The following paragraphs present a brief analysis of a representative sample of previous empirical studies.

Saini, Nigam, and Misra [15] examined the success factors for implementing ERP systems at Indian SMEs. Their sample included 164 companies, while the empirical data were analysed using the statistical z-test. Support was found for all hypotheses, arguing that technological factors 
(e.g. system testing, IT infrastructure), people factors (e.g. cross-functional team, morale of the implementation team), and organizational factors (e.g. adaptability to changes, comprehensiveness of the implementation strategy) have a direct impact on the success of ERP implementation [15].

Garg and Chauhan [20] explored the factors affecting the success of ERP implementation in the Indian retail sector. Their conceptual framework, which included various critical success factors, explained $62,7 \%$ of the variations of ERP implementation success. As with Saini, Nigam, and Misra [15], organizational, technological, and people-related factors were found to be significant antecedents of ERP implementation success. Additionally, the impact of project management was, also, identified as being significant [20]. Garg and Garg [8] in another similar study that was, also, conducted in the Indian retail sector, found out that strategic, technological, people and project management factors have a positive influence on ERP implementation success.

Chien, Lin, and Shih [10] investigated the impact of centrifugal and centripetal forces on team cohesion and successful ERP implementation. Their empirical results were based on a survey of 305 Taiwanese SMEs. It was found that centripetal forces have a significant impact on ERP implementation, while the same was not verified for centrifugal forces, as well. Finally, team cohesion seemed to moderate the relationship between centripetal forces and ERP implementation performance [10].

Zabjek, Kovacic, and Indihar Stemberger [9] identified business process management as an important antecedent of ERP effective implementation. Their analysis was based on 152 questionnaires collected from Slovenian companies. They concluded that top management support, change management and business process management have a positive impact on successful ERP implementation [9]. The same authors conducted another similar research [16], obtaining identical results. On the same vein, Garg and Agarwal [21], also, underlined the significance of top management commitment, user involvement, business process reengineering, project management and ERP teamwork and composition on the success of ERP implementation [21].

Li, Markowski, Xu, and Markowski [29] used Structural Equation Modeling (SEM) in order to analyze data from 154 manufacturing companies operating in the USA. Their analysis revealed that Total Quality Management (TQM) is an important predecessor of ERP implementation. Chou, Hung, and Chang [30] focused on ERP organizational fit and knowledge transfer. They concluded that ERP success is influenced by organizational fit (data fit, process fit, user fit), ERP knowledge factors (e.g. shared understanding), and ERP communication factors (e.g. communication decoding competence), either directly or indirectly [30].

On a different approach, Amid, Moalagh, and Ravasan [31] focused on Critical Failure Factors (CFFs), rather that Critical Success Factors (CSFs). Firstly, they conducted semi-structured interviews with practitioners, identifying 47 failure factors. Secondly, they collected empirical data with the use of a structured questionnaire. Using Exploratory
Factor Analysis (EFA), they classified CFFs in seven large groups (vendor and consultant, human resources, managerial, project management, processes, organizational, technical). Their research was conducted on a developing country, namely Iran [31].

Wee [32] underlined the importance of formulating an overall ERP architecture before the deployment of the system, since only in such a way the need for reconfiguration during, or after, its real-time implementation will significantly diminish. Similar views were supported by other authors, arguing that the use of proper and formal modelling methods, tools and architectures is necessary for ERP implementation success [33]. Ferratt, Ahire, and De [34] argued that implementing organisations need to follow the basics of project management and, simultaneously, adopt the best industry practices in order to successfully implement an ERP system.

Ngai, Law, and Wat [35] focused on the importance of national culture and country-related characteristics on ERP implementation success. Sheu, Chae and Yang [36] underlined the impact of different cultural backgrounds, while Tarafdar and Roy [37] analysed the cultural issues that a typical Indian firm, usually, faces when implementing an ERP system. Finally, Lee, Lee, and Kang [38] argued that implementation success largely depends upon the attitude of the employees towards the whole ERP project.

As it became evident from the previous paragraphs, contemporary research includes a wide range of critical factors predicting ERP implementation success, ranging from vendor selection [39], to project management aspects [14] [40]. However, most of these studies are focused on larger enterprises [41]. On the other hand, ERP adoption by SMEs has traditionally received less attention from the international literature. According to Poba-Nzaou, Raymond and Fabi [41], this represents an area for additional research, especially since SMEs face greater difficulties in adopting ERP systems.

In summary, the literature includes the following gaps: (a) There is a multitude of critical success factors (antecedents) that have been used in order to predict ERP implementation success. Therefore, one is unable to determine which are actually the most important. The need for additional research is imperative; (b) The focus on SMEs has been limited; (c) Very few studies have utilised specific criteria for selecting certain factors, and excluding others, from their analysis. Selecting factors without justification is considered as a significant limitation; (d) Few of the published empirical studies were carried out in European countries; (e) Very few studies built on previous research. The present study was designed so as to cover these limitations (research gaps) found in the relevant literature.

\section{CONCEPTUAL FRAMEWORK}

As mentioned earlier, the present study aims to: (a) built a coherent conceptual framework including the most significant antecedents of ERP implementation success and (b) test that framework gathering quantitative data. 
The literature review analysis that was conducted prior to the development of the conceptual framework of the present study revealed that numerous factors have been used in order to predict ERP implementation success. Therefore, an important challenge was to decide upon the factors that were going to be incorporated into the proposed conceptual framework. The main objective was to construct a conceptual framework that incorporates the most significant factors used in the literature. Moreover, the incorporated factors were expected to have a high degree of relevance with the overall context of the study (Greek SMEs).

In order to address that critical issue, a qualitative research was conducted prior to the quantitative research. More analytically, a 'panel of experts' was formed in order to evaluate the factors that have been used in the relevant literature and assist in selecting the most appropriate ones for the proposed conceptual framework of the present study. More specifically, the focus group methodology was used.

This approach offers certain benefits: (a) the selection of the factors that were, finally, incorporated in the proposed conceptual framework was not conducted according to the subjective judgment of the researchers, but was a result of a more coherent and objective procedure, (b) the proposed conceptual framework has a strong basis on the opinions of experienced practitioners (managers of SMEs), (c) the selection of factors with low significance was avoided. It is believed that the random selection of the research factors, without any theoretical or empirical justification, would have resulted in the limited reliability of the present study.

In order to enhance the validity of the qualitative research, two sessions held in different geographical areas were conducted. All companies were selected in random, using data from the Chamber of Commerce. Each focus group included five managers of SMEs. This approach is in line with the main principles of the focus group methodology [42], since there was an appropriate number of participants for each session, two different sessions with different participants were conducted, while the represented companies were randomly selected.

The participants of each group were given (in paper) an extensive list of factors that have been used in the literature in order to predict ERP successful implementation. Then, a detailed conversation was conducted, with two members of the research team acting as moderators [43]. Each focus group took approximately two hours. Notes were taken during each session by a second moderator, while additional notes were added after reviewing the recorded sessions. After long discussions and deliberations, each focus group unanimously chose the nine most important factors of the provided list. The two focus groups agreed, with minor exceptions, in the same factors.

The conceptual framework of the present study incorporates these nine (independent) factors, resulting from the qualitative research, and one dependent factor, namely ERP implementation success. Additionally, 'organisational impact' was added in the proposed conceptual framework, in order to investigate the effect of ERP implementation on various measures of organisational performance.
The nine independent factors are listed below: Top management support, Organizational culture, External pressure, Vendor support, Project management, Training, User involvement, Business Process Reengineering, Implemented modules.

A. Top management support could be easily defined as the involvement of business executives in the areas related with ERP implementation [44]. It has been highlighted, by several authors, as a critical factor for the successful implementation of ERP systems [14] [45] [46].

Ngai, Law, and Wat [35] argued that senior executives play a significant role in ERP implementation success, since these projects are, usually, time consuming and demand extensive financial support. Senior management has two roles during implementation: supplying funds and offering leadership [14]. Al-Mashari, Al-Mudimigh, and Zairi [47] insisted that senior management support should be offered, without disruption, during the whole implementation period. The tasks of senior executives when implementing ERP projects include: communicating the strategy to all business employees, setting limitations, proving engagement, and setting reasonable goals [46]. Participation, support, and senior-level sponsorship are dimensions that have been found to significantly affect ERP implementation [48] [49].

ERP implementation does not, exclusively, evolve around software reengineering. On the contrary, it includes the extensive restructuring of business processes. Consequently, senior executives must clearly, publicly and truly indicate their support (economic or not), in order to highlight the priority given to implementation [48] [49]. Therefore:

H1: Top management support has a direct positive effect on ERP implementation success.

B. Organizational culture represents the shared ideologies, standards, convictions that have an impact on organizational attitudes and activities [50].

A common culture, shared between various organizational members, has an impact on the willingness to change, e.g. to adopt a new Information System. Research has shown that organizational culture is quite significant for the success of most organizational changes [51] [52]. Jarvenpaa and Staples [52] argue that there should be a fit between the culture of the organization and the nature of the changes that may occur from implementing an ERP system.

Additionally, according to Jones, Cline, and Ryan [51], organizational culture has an effect on employee behavior towards knowledge sharing, while knowledge sharing is crucial for the successful implementation of ERP systems. Ruppel and Harrington [53] argue that organizational culture has an effect on the implementation of intranet and other information systems used inside the organisation. Hence, it can be hypothesised that:

H2: Organizational culture has a direct positive effect on ERP implementation success.

C. Sometimes, the implementation of an ERP system does not have intrinsic motives. On the contrary, companies are being forced to implement an Information System, either by 
their supply chain partners or by their competitors [54] [55]. In the first case, implementation becomes a prerequisite for the continuous cooperation with a partner (supplier and/or customer), while in the second case, the adoption decision is based on the need to follow the competitors, and, hence, avoid any possible downturn from not doing so [56].

In the present study, it is hypothesised that when companies find themselves under pressure from the external environment, they tend to try harder to achieve their desired goals. Therefore, the higher the external pressure, the more successful the implementation of the ERP system.

H3: External pressure has a direct positive effect on ERP implementation success.

D. Vendor support is offered from software retailers and/or consulting companies [4]. In most of the cases, the retailer is, also, the consultant during, or after, the implementation.

Vendor support includes user training, extended technical assistance during and after the implementation, maintenance, updates, etc. Additionally, vendors offer analytical advice concerning the selection of the appropriate ERP software [57] [58]. According to Wang, Lin, Jiang, and Klein [57], vendors significantly enhance the effectiveness of the implemented system, via experience sharing and knowledge transfer.

Through continuous collaboration, formal training and knowledge dissemination, consultants assist their costumers in receiving the full benefits of the implemented system [57] [59]. The trustworthiness of the vendor is extremely important in determining the success, or the failure of the whole effort [60]. Koh, Simpson, Padmore, Dimitriadis, and Misopoulos [60] found out that the close relationship with the vendor is a critical success factor for the implementation of an ERP system.

H4: Vendor support has a direct positive effect on ERP implementation success.

E. The implementation of an ERP system is a risky and complex project [21]. As it is evident, such projects acquire excellent management, since numerous stakeholders (different business units, suppliers, customers, vendors/ consultants) are deeply involved [15] [20]. The manager of an ERP project should bear in mind different timetables, various milestones, equipment requirements, workforce availability, and budget needs [49]. Hence, successful implementation is synonymous with the management of a plethora of tasks. All these tasks should be carefully monitored and managed.

More specifically, standard meetings and reports should be provided for all project collaborators. Effective project management is very crucial, since implementation success is, usually, assessed on the basis of budget and time compliance [21]. Executives expect the implementation period to be completed on time, and on budget.

H5: Project management has a direct positive effect on ERP implementation success.
F. Training is considered to be a basic parameter in every ERP implementation project [45] [46]. Hong and Kim [27] argue that training should be provided before, during and after implementation, while both technical and procedural issues should be carefully addressed. Finally, in-house training (on-the-job training) appears to be the most efficient choice, between all available methods [14].

Dezdar and Ainin [61] argued that sufficient training allows employees to efficiently utilize the implemented ERP system. More specifically, training enhances the skills and increases the practical expertise of real-time users [62]. Nah, Zuckweiler, and Lau [63] found out that adequate training enhances implementation success, while lack of training undermines the whole process. Additionally, sufficient training builds a positive climate towards the implemented system, thus, increasing its use and overall acceptance. Moreover, training enhances the ease of use, which in turn increases the probability for system success [62].

H6: Training has a direct positive effect on ERP implementation success.

G. User involvement is one of the most influential factors in ERP implementation projects [14] [27] [47]. Numerous studies argue that users should be actively involved before and during the entire ERP implementation process [8]. This will ensure that the system has a better fit with business processes, since its development will be based on real needs. Moreover, the acceptance of the ERP system will be increased, since users will have participated in its development. Finally, resistance to change will be significantly decreased [8] [47].

According to various authors [20], user involvement increases user satisfaction and user acceptance, by developing realistic expectations about the capabilities of the system. Additionally, user involvement increases the perceived level of control, through user participation in the entire project [20]. When all the above conditions are being successfully met, the implementation of the ERP system will be much more efficient.

H7: User involvement has a direct positive effect on ERP implementation success.

H. Business Process Reengineering (BPR) is the fundamental rethinking and drastic redesign of business processes, in order to achieve improvements in critical measures, such as cost, quality, delivery, and speed [49] [64]. ERP implementation requires such a radical redesign of business processes, since the new ERP system is expected to drastically change several aspects of doing business [40].

It is the ERP system that underlines the necessity for BPR and forces the organization to redefine and redesign work flows in order to fit the new software [40]. Reengineering business processes in a way that makes them compatible with the implemented system appears as an important antecedent of ERP implementation success [64].

H8: Business Process Reengineering (BPR) has a direct positive effect on ERP implementation success. 
I. ERP systems may be implemented in modules. A company does not have to conduct a full scale implementation; on the contrary, certain modules could be implemented on the basis of its special needs and requirements [65]. According to Yeh, Yang, and Lin [66], it would be unwise to avoid implementing most of the available modules, since only full implementation really ensures the expected benefits. Some empirical studies have argued that there is a relationship between the number of implemented modules and the functional effectiveness of the ERP system [67]. After all, the more modules a company implements, the higher its benefits from cross-operational cooperation [65].

H9: The number of implemented modules has a direct positive effect on ERP implementation success.

J. The construct of "organizational performance", as it has been captured in the present study, includes measures of multiple dimensions, such as productivity, cycle time, cost reduction, information flow, and customer satisfaction. Its main goal is to include both qualitative and quantitative measures of organisational performance. Law and Ngai [68] followed a similar approach. Many previous studies have investigated the impact of ERP implementation on firm performance [69] [70], while its impact on organisational performance has received less empirical examination. Therefore, it is hypothesised:

H10: ERP implementation success has a direct positive effect on organizational performance.

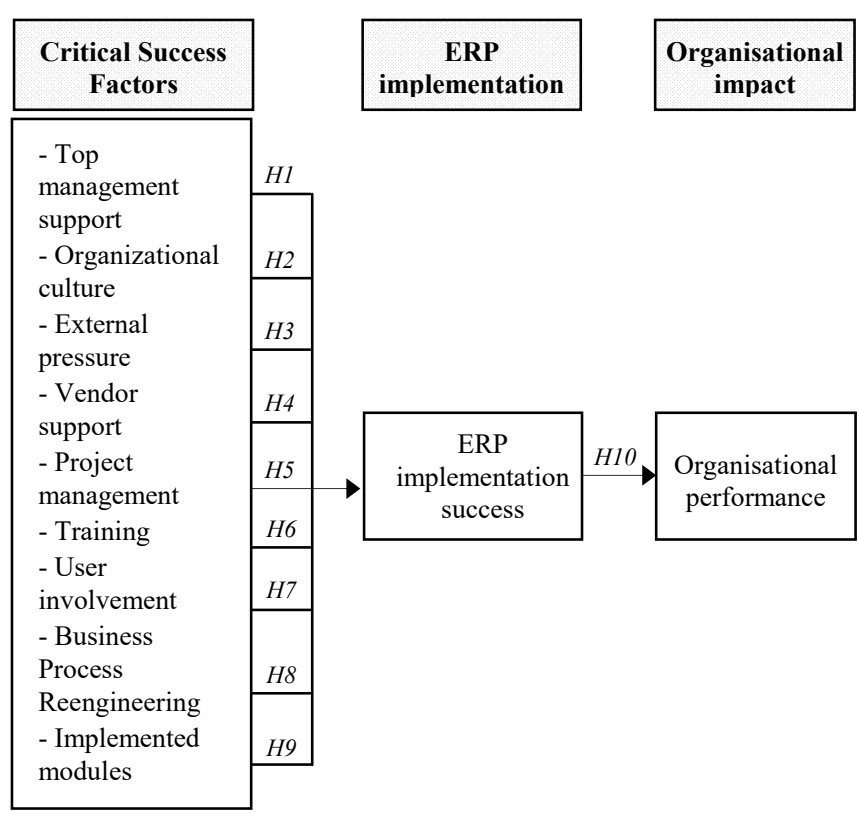

Fig. 1 The proposed conceptual framework

The synthesis of the hypotheses presented above formulates the proposed conceptual framework of the present study (Fig. 1). It should be underlined that, according to the best of the researcher's knowledge, such a conceptual framework (combination of factors) has never been examined before in the literature.

\section{RESEARCH METHODOLOGY}

\section{A. Population of the study}

The population of the present study includes Greek Small and Medium Enterprises (SMEs) that have implemented an ERP system. There are no available official data that can define the population of the study on numerical terms.

SMEs are considered to be the heart of the Greek economy, since they represent $99 \%$ of the total number of companies. In 2010, there were 742.000 SMEs, with 2.512.493 employees, which represent more than $75 \%$ of total employment, well above the EU average. Greece has a very high share of SMEs, particularly micro enterprises, compared to the EU average (Annual Report on EU SMEs 2010/2011, 2011).

\section{B. Measurement}

The proposed conceptual framework was tested with the use of a newly-developed structured questionnaire. The measurement of the eleven research factors was conducted with the use of multiple questions (items) that were adopted from the international literature [14] [15] [20] [27] [51] [52] [54] [55] [56] [58] [59] [65] [66] [68]. All questions were translated to Greek and then back to English by another person, in order to detect any discrepancies. The five-point Likert scale was used for the measurement of all factors.

\section{Data collection}

Data concerning companies that could possibly be included in the sample were obtained via the web sites of the leading ERP system providers operating in Greece. Since no other database including companies using ERP systems exist, the use of the certain method was the only one able to provide usable information. Totally, 678 companies that have implemented an ERP system were identified. The questionnaire and a cover letter including clarifications, was sent to the IT managers of these companies.

Questionnaires were sent only after a telephonic contact with the IT manager in each company has been established. After making all necessary telephone calls, 421 questionnaires were distributed to 421 companies that agreed to participate in the survey. The research period lasted three months (March to May 2015). Totally, 165 questionnaires were returned, and after conducting all necessary controls 159 were used for data analysis. The 159 questionnaires represent a very satisfactory response rate (38\%). The majority of the participating companies are small sized (less than 100 employees), something that is in line with the country's average firm size.

\section{Reliability and validity}

The questionnaire that was used in the present study was rigorously tested for its content and construct validity.

The test for the content validity was conducted via a pilot study. More specifically, a draft of the final questionnaire was sent to four practitioners and two academics, in order to test whether it met all theoretical and practical requirements. 
TABLE I. $\quad$ ESTIMATION OF UNIDIMENSIONALITY AND RELIABILITY

\begin{tabular}{|l|c|c|c|c|c|}
\hline \multicolumn{1}{|c|}{ Factors } & KMO & $\begin{array}{c}\text { Bartlett's } \\
\text { Test }\end{array}$ & $\begin{array}{c}\text { Eigen- } \\
\text { value }\end{array}$ & TVE & $\begin{array}{c}\text { Cronbach } \\
\text { Alpha }\end{array}$ \\
\hline Top management support & 0,736 & $139,2^{\mathrm{a}}$ & 2,546 & $67,3 \%$ & 0,789 \\
\hline Organizational culture & 0,894 & $214,9^{\mathrm{a}}$ & 2,871 & $71,5 \%$ & 0,823 \\
\hline External pressure & 0,779 & $77,5^{\mathrm{a}}$ & 1,371 & $68,4 \%$ & 0,801 \\
\hline Vendor support & 0,831 & $145,6^{\mathrm{a}}$ & 2,874 & $81,7 \%$ & 0,745 \\
\hline Project management & 0,799 & $154,2^{\mathrm{a}}$ & 1,741 & $84,7 \%$ & 0,771 \\
\hline Training & 0,854 & $95,5^{\mathrm{a}}$ & 2,713 & $71,9 \%$ & 0,723 \\
\hline User involvement & 0,736 & $214,3^{\mathrm{a}}$ & 2,124 & $76,2 \%$ & 0,755 \\
\hline $\begin{array}{l}\text { Business Process } \\
\text { Reengineering }\end{array}$ & 0,711 & $325,3^{\mathrm{a}}$ & 2,587 & $74,1 \%$ & 0,737 \\
\hline Implemented modules & 0,857 & $217,6^{\mathrm{a}}$ & 1,342 & $83,4 \%$ & 0,741 \\
\hline $\begin{array}{l}\text { ERP implementation } \\
\text { success }\end{array}$ & 0,839 & $169,7^{\mathrm{a}}$ & 1,619 & $84,5 \%$ & 0,901 \\
\hline $\begin{array}{l}\text { Organisational } \\
\text { performance }\end{array}$ & 0,759 & $171,3^{\mathrm{a}}$ & 2,391 & $88,6 \%$ & 0,733 \\
\hline
\end{tabular}

TABLE II. ESTIMATION OF THE GOODNESS OF FIT

\begin{tabular}{|l|c|c|c|c|c|}
\hline \multicolumn{1}{|c|}{ Factors } & $\begin{array}{c}\text { Normed } \\
\boldsymbol{X}^{\mathbf{2}}\end{array}$ & $\boldsymbol{C . R .}$ & $\boldsymbol{V} . \boldsymbol{E}$. & $\boldsymbol{R M S E A}$ & $\begin{array}{c}\boldsymbol{C F I} / \\
\boldsymbol{G F I}\end{array}$ \\
\hline Top management support & 1,57 & 0,78 & $65,6 \%$ & 0,077 & $0,94 / 0,96$ \\
\hline Organizational culture & 2,67 & 0,74 & $69,4 \%$ & 0,053 & $0,97 / 0,97$ \\
\hline External pressure & 3,15 & 0,86 & $0,81 \%$ & 0,067 & $0,99 / 0,97$ \\
\hline Vendor support & 3,52 & 0,82 & $0,76 \%$ & 0,084 & $0,91 / 0,93$ \\
\hline Project management & 2,19 & 0,76 & $0,67 \%$ & 0,075 & $0,99 / 0,98$ \\
\hline Training & 1,97 & 0,77 & $0,63 \%$ & 0,063 & $0,90 / 0,93$ \\
\hline User involvement & 2,37 & 0,69 & $0,57 \%$ & 0,086 & $0,95 / 0,99$ \\
\hline $\begin{array}{l}\text { Business Process } \\
\text { Reengineering }\end{array}$ & 2,45 & 0,73 & $0,81 \%$ & 0,059 & $0,90 / 0,90$ \\
\hline Implemented modules & 2,65 & 0,83 & $0,74 \%$ & 0,061 & $0,91 / 0,96$ \\
\hline $\begin{array}{l}\text { ERP implementation } \\
\text { success }\end{array}$ & 2,77 & 0,77 & $0,64 \%$ & 0,074 & $0,93 / 0,91$ \\
\hline $\begin{array}{l}\text { Organisational } \\
\text { performance }\end{array}$ & 1,61 & 0,74 & $0,61 \%$ & 0,081 & $0,93 / 0,95$ \\
\hline
\end{tabular}

TABLE III. RESUlts OF THE STRUCTURAL MODEL

\begin{tabular}{|c|l|c|c|c|}
\hline \multicolumn{2}{|c|}{ Causal Paths (hypotheses) } & Estimate & $\boldsymbol{p}$ & Result \\
\hline $\mathrm{H} 1$ & $\begin{array}{l}\text { Top management support } \rightarrow \\
\text { ERP implementation success }\end{array}$ & 0,26 & 0,000 & Accepted \\
\hline $\mathrm{H} 2$ & $\begin{array}{l}\text { Organizational culture } \rightarrow \\
\text { ERP implementation success }\end{array}$ & 0,23 & 0,000 & Accepted \\
\hline H3 & $\begin{array}{l}\text { External pressure } \rightarrow \\
\text { ERP implementation success }\end{array}$ & - & 0,098 & Rejected \\
\hline H4 & $\begin{array}{l}\text { Vendor support } \rightarrow \\
\text { ERP implementation success }\end{array}$ & 0,36 & 0,011 & Accepted \\
\hline H5 & $\begin{array}{l}\text { Project management } \rightarrow \\
\text { ERP implementation success }\end{array}$ & - & 0,267 & Rejected \\
\hline H6 & $\begin{array}{l}\text { Training } \rightarrow \\
\text { ERP implementation success }\end{array}$ & 0,29 & 0,000 & Accepted \\
\hline H7 & $\begin{array}{l}\text { User involvement } \rightarrow \\
\text { ERP implementation success }\end{array}$ & 0,26 & 0,000 & Accepted \\
\hline H8 & $\begin{array}{l}\text { Business Process Reengineering } \rightarrow \\
\text { ERP implementation success }\end{array}$ & 0,35 & 0,000 & Accepted \\
\hline H9 & $\begin{array}{l}\text { Implemented modules } \rightarrow \\
\text { ERP implementation success }\end{array}$ & - & 0,164 & Rejected \\
\hline H10 & $\begin{array}{l}\text { ERP implementation success } \rightarrow \\
\text { Organisational performance }\end{array}$ & 0,34 & 0,003 & Accepted \\
\hline
\end{tabular}

To test the construct validity, each research factor was evaluated: (a) for its unidimensionality and reliability (Table I), (b) for its goodness of fit to the proposed research model (Table II). The examination of the unidimensionality of each factor was conducted using Explanatory Factor Analysis (EFA) [71]. Moreover, 'Cronbach Alpha' was used for estimating each factor's reliability. All tests concluded that the scales used are valid and reliable.

The evaluation of the goodness of fit of each research factor to the proposed model was conducted using Confirmatory Factor Analysis (CFA). All tests produced satisfactory results (see Table II for the main results).

\section{EMPIRICAL RESULTS}

\section{A. Model valuation}

The examination of the proposed conceptual framework was conducted using the "Structural Equation Modeling" (SEM) technique [72] [73] [74]. To evaluate the fit of the overall model the chi-square value $\left(X^{2}=49,7\right)$ and the $p$ value $(p=0,000)$ were estimated. These values indicate a satisfactory fit. However, the sensitivity of the $\mathrm{X}^{2}$ statistic to the sample size enforces to control other supplementary measures of evaluating the overall model, such as the "Normed-X"' index $(3,1)$, the RSMEA index $(0,077)$ the CFI $(0,99)$ and the GFI $(0,97)$, that all indicate a good fit.

\section{B. Hypothesis testing}

Seven hypotheses were found significant $(\mathrm{H} 1, \mathrm{H} 2, \mathrm{H} 4$, H6, H7, H8, H10), while three hypotheses were rejected by the empirical data (H3, H5, H9). After reviewing the empirical results, the following observations can be made:

A. The successful implementation of an ERP system has its roots on vendor support, training, and user involvement. These three factors were found to have the strongest impact on the main dependent factor of the present study (ERP implementation success). According to these empirical results, the present study proposes a mechanism that will drive implementation success. Various organisations may utilise this mechanism in order to experience a seamless implementation process. It includes three steps, each describing tasks that should be performed before, during and after the implementation of an ERP system.

Firstly, before the implementation, companies should spend their limited time and resources in selecting the appropriate software retailer. A good fit between the two seems to be very crucial for implementation success. Moreover, employees should be involved in the decision to adopt an ERP system. Executives should take employee attitudes and beliefs under serious consideration. In general, employees should feel like an integrated part of the whole process, while the adoption of the new system should not be understood as a decision that has been forced upon them. Only when employees fell like they have contributed to the implementation initiative, will they accept the changes that may occur. On a more practical level, the contribution of employees before the implementation is crucial for ensuring that the system will be designed in order to have a better fit with existing business practices.

Secondly, during the implementation period (that may be quite short, especially in micro-enterprises), vendors should adopt an analytical (linear) approach. Initially, the most 
technological-ready employees should be selected in order to test the implemented system. Then, its advantages should be underlined and communicated amongst all personnel. After that, initial training should take place. The main goal is to initiate the system after all employees have been fully involved in the whole process.

Thirdly, after the implementation period, continuous training should be offered by the vendor (or another consultant). After all, the first month following the implementation of the new ERP system is extremely crucial. Employees should feel that the new system enhances their job, while resulting in many other organisational benefits.

B. No matter how important the role of vendor support $(\mathrm{r}=0,36)$, training $(\mathrm{r}=0,29)$, and user involvement $(\mathrm{r}=0,26)$, the support of top management has, also, been underlined as a significant antecedent of ERP implementation success $(\mathrm{r}=0,26)$. Without any doubt, executives should demonstrate their belief on the implemented system, mostly by ensuring its funding and setting the example for its use.

C. Moreover, the empirical data revealed that Business Process Reengineering (BPR) is a quite significant factor $(\mathrm{r}=0,35)$. This finding adds further support to the previous observations, arguing that BPR should be a priority for vendors, employees and executives.

D. Additionally, organizational culture (with emphasis on knowledge-sharing) affects implementation $(\mathrm{r}=0,23)$. This factor cannot be easily enhanced prior or during the implementation period, since its development is, usually, a result of the unique history of the organisation.

Finally, the relationship between ERP implementation success and organisational performance has been verified by the empirical data $(r=0,34)$. Concerning the strength of that relationship $\left(\mathrm{R}^{2}=26 \%\right.$, including direct and indirect effects), it should be noted that when examining complex phenomena, like organisational performance, even a relatively small predictive power seems to be satisfactory.

\section{CONCLUSIONS}

The present study was motivated by specific gaps that were recognised in the relevant literature of the specific field. In order to cover these gaps, the present study used an extensive literature review and qualitative data (focus group sessions with managers of SMEs) in order to develop a conceptual framework that investigated the antecedents of ERP implementation success. Moreover, this framework was tested with the use of a newly-developed structured questionnaire (quantitative data) on a sample of Greek SEMs that have implemented and ERP system.

That specific approach offered certain advantages: focus groups offered practical knowledge concerning the factors with the most significant impact on ERP implementation, while the quantitative research revealed which of these factors are actually significant. The contribution of the study lies on this enhanced approach. More specifically, it offers the necessary ground for comparison and replication. Its conceptual framework may be replicated from future studies, while other scientists may employ its twofold approach as a basis for their future empirical investigation.
The proposed conceptual framework of the study included nine antecedents of ERP implementation success. These factors are perceived as Critical Success Factors (CSFs) for successful ERP implementation. Empirical data were analysed using the "Structural Equation Modeling" (SEM) technique, while the validity and the reliability of all research factors were evaluated with the use of enhanced statistical methods (EFA, CFA).

According to the results of the statistical analysis, six of the antecedents included in the research model of the present study were found to have a direct (positive) effect on successful ERP implementation. Additionally, the predictive power of the proposed model was found to be very satisfactory. More specifically, the six antecedents can explain the variance of ERP successful implementation by $72 \%\left(\mathrm{R}^{2}=0,72\right)$. On the other hand, three research factors (external pressure, project management, implemented modules) were not found to have an effect on the successful implementation of an ERP system.

Therefore, it is concluded that when implementing an ERP system, organisations should focus on the following six factors: Top management support, Organizational culture, Vendor support, Training, User involvement, Business Process Reengineering. The present study argues that the enhancement of these Critical Success Factors should be conducted before, during and after ERP implementation. Partial focus will only limit their positive effect.

In general, it is concluded that ERP implementation success is a result of intangible factors (organisational culture), people-related factors (vendor support, training, user involvement), and proper leadership (top management support). Moreover, reengineering, a more practical issue of implementation, is also a prerequisite for success.

Previous studies conducted in other geographical regions of the European continent (e.g. Eastern and Central Europe) have found similar results. For example, Ziemba and Kolasa [61] found that top management support, user involvement and process management have an impact on information systems projects, while Bradley [62] concluded that the determinants of enterprise system adoption success are user involvement, user empowerment, system reliability and cooperation with the system supplier (vendor).

The present study is somehow limited by the poor definition of its population. This limitation is inherent to all studies of the field, since a complete list of companies that have implemented an ERP system can not be found in most databases. Further research is suggested with larger samples that would, probably, offer more information and strengthen the results of the present study. Moreover, it would be interesting to examine more factors and gather primary data from all company personnel, so as to achieve a more complete view of the subject under investigation.

\section{REFERENCES}

[1] C. Leyh, "Critical success factors for ERP projects in small and medium-sized enterprises-The perspective of selected German SMEs", IEEE Federated Conference on Computer Science and Information Systems (FedCSIS), pp. 1181-1190, 2014. 
[2] C. Spathis, and S. Constantinides, "Enterprise resource planning systems' impact on accounting processes", Business Process Management Journal, Vol. 10, No. 2, pp. 234-247, 2004, http://dx.doi. org/10.1108/14637150410530280.

[3] M. Lobaziewicz, "Integration of B2B system that supports the management of construction processes with ERP systems", IEEE Federated Conference on Computer Science and Information Systems (FedCSIS), pp. 1461-1466, 2015.

[4] M.T. Tsai, E.Y. Li, K.W. Lee, and W.H. Tung, "Beyond ERP implementation: the moderating effect of knowledge management on business performance", Total Quality Management, Vol. 22, No. 2, pp. 131-144, 2011, http://dx.doi.org/10.1080/14783363.2010.529638.

[5] H.R. HassabElnaby, W. Hwang, and M.A. Vonderembse, "The impact of ERP implementation on organizational capabilities and firm performance", Benchmarking: an International Journal, Vol. 19, No. 4/5, pp. 618-633, 2012, http://dx.doi.org/10.1108/14635771211258043.

[6] P. Ifinedo, B. Rapp, A. Ifinedo, and K. Sundberg, "Relationships among ERP post-implementation success constructs: an analysis at the organizational level", Computers in Human Behavior, Vol. 26, No. 5, pp. 1136-1148, 2010, http://dx.doi.org/ 10.1016/j.chb.2010.03.020.

[7] V.A. Mabert, A. Soni, and M.A. Venkatraman, "The impact of organizational size on enterprise resource planning (ERP) implementation in the US manufacturing sector", Omega, Vol. 31, pp. 235-246, 2003, http://dx.doi.org/10.1016/S0305-0483(03)00022-7.

[8] P. Garg, and A. Garg, "Factors influencing ERP implementation in retail sector: an empirical study from India", Journal of Enterprise Information Management, Vol. 27, No. 4, pp. 424-448, 2014, http:// dx.doi.org/10.1108/JEIM-06-2012-0028.

[9] D. Zabjek, A. Kovacic, and M. Indihar Stemberger, "Business process management as an important factor for a successful ERP system implementation", Ekonomska istrazivanja, Vol. 21, No. 4, pp. 1-18, 2008.

[10] S.W. Chien, H.C. Lin, and C.T. Shih, "A Moderated Mediation Study: Cohesion Linking Centrifugal and Centripetal Forces to ERP Implementation Performance", International Journal of Production Economics, Vol. 158, pp. 1-8, 2014, http://dx.doi.org/10.1016/j.ijpe. 2014.06.001.

[11] A.I. Nicolaou, and S. Bhattacharya, "Organizational performance effects of ERP systems usage: the impact of post-implementation changes", International Journal of Accounting Information Systems, Vol. 7, No. 1, pp. 18-35, 2006, http://dx.doi.org/10.1016/j.accinf.200 5.12 .002 .

[12] J.R. Muscatello, and I.J. Chen, "Enterprise resource planning (ERP) implementations: theory and practice", International Journal of Enterprise Information Systems, Vol. 4 No. 1, pp. 63-78, 2008.

[13] D. Lee, S.M. Lee, D.L. Olson, and S. Hwan Chung, "The effect of organizational support on ERP implementation", Industrial Management \& Data Systems, Vol. 110, No. 2, pp. 269-283, 2010, http://dx.doi.org/10.1108/02635571011020340.

[14] Z. Zhang, M.K. Lee, P. Huang, L. Zhang, and X. Huang, "A framework of ERP systems implementation success in China: an empirical study", International Journal of Production Economics, Vol. 98, No. 1, pp. 56-80, 2005, http://dx.doi.org/ 10.1016/j.ijpe.2004.09.004.

[15] S. Saini, S. Nigam, and S.C. Misra, "Identifying success factors for implementation of ERP at Indian SMEs: a comparative study with Indian large organizations and the global trend", Journal of Modelling in Management, Vol. 8, No. 1, pp. 103-122, 2013, http://dx.doi.org/10. $1108 / 17465661311312003$

[16] D. Zabjek, A. Kovacic, and M. Indihar Stemberger, "The influence of business process management and some other CSFs on successful ERP implementation", Business Process Management Journal, Vol. 15, No. 4, pp. 588-608, 2009, http://dx.doi.org/10.1108/14637150910 975552.

[17] R.D. Samuel, and S. Kumar, "Prediction of ERP Success before the Implementation", in International Asia Conference on Industrial Engineering and Management Innovation (IEMI2012) Proceedings, pp. 219-227, 2013, http://dx.doi.org/ 10.1007/978-3-642-38445-5_22.

[18] E.J. Umble, and M.M. Umble, "Avoiding ERP implementation failure”, Industrial Management, Vol. 44, No. 1, pp. 25-33, 2002.

[19] J. Ram, D. Corkindale, and M.L. Wu, "Implementation critical success factors (CSFs) for ERP: do they contribute to implementation success and post-implementation performance?", International Journal of
Production Economics, Vol. 144, No. 1, pp. 157-174, 2013, http://dx. doi.org/10.1016/j.ijpe.2013.01.032.

[20] P. Garg, and A. Chauhan, "Factors affecting the ERP implementation in Indian retail sector", Benchmarking: an International Journal, Vol. 22, No. 7, pp. 1315-1340, 2015, http://dx.doi.org/10.1108/BIJ-112013-0104.

[21] P. Garg, and D. Agarwal, "Critical success factors for ERP implementation in a Fortis hospital", Journal of Enterprise Information Management, Vol. 27, No. 4, pp. 402-423, 2014, http://dx.doi.org/10.1 108/JEIM-06-2012-0027.

[22] J. Ram, and D. Corkindale, "How "critical" are the critical success factors (CSFs)? Examining the role of CSFs for ERP", Business Process Management Journal, Vol. 20, No. 1, pp. 151-174, 2014, http://dx.doi.org/10.1108/BPMJ-11-2012-0127.

[23] J.F. Rockart "A new approach to defining the chief executive's information needs", MIT Working Paper, CISR 37, No. 1008-78, 1978.

[24] R. Saade, and H. Nijher, "Critical success factors in enterprise resource planning implementation: a review of case studies", Journal of Enterprise Information Management, Vol. 29, No. 1, pp. 72-96 , 2016 , http://dx.doi.org/10.1108/JEIM-03-2014-0028.

[25] A. Boynton, and R. Zmud, "An assessment of critical success factors", Sloan Management Review, Vol. 25, No. 4, pp. 17-27, 1984.

[26] P. Bingi, M.K. Sharma, and J.K. Godla, "Critical issues affecting an ERP implementation”, IS Management, Vol. 16, No. 3, pp. 7-14, 1999, http://dx.doi.org/10.1201/1078/43197.16.3.19990601/31310.2.

[27] K.K. Hong, and Y.G. Kim, "The critical success factors for ERP implementation: an organizational fit perspective", Information \& Management, Vol. 40, No. 1, pp. 25-40, 2002, http://dx.doi.org/10.101 6/S0378-7206(01)00134-3.

[28] J. Motwani, R. Subramanian, and P. Gopalakrishna "Critical factors for successful ERP implementation: exploratory findings from four case studies", Computers in Industry, Vol. 56, No. 6, pp. 529-544, 2005, http://dx.doi.org/10.1016/j.compind.2005.02.005.

[29] L. Li, C. Markowski, L. Xu, and E. Markowski, "TQM - A predecessor of ERP implementation", International Journal of Production Economics, Vol. 115, No. 2, pp. 569-580, 2008, http://dx. doi.org/10.1016/j.ijpe.2008.07.004.

[30] S.W. Chou, I.H. Hung, and Y.C. Chang, "Understanding the antecedents of ERP Implementation success - The Perspective of Knowledge Transfer", Asia Pacific Management Review, Vol. 18, No. 3, pp. 301-322, 2013.

[31] A. Amid, M. Moalagh, and A.Z. Ravasan, "Identification and classification of ERP critical failure factors in Iranian industries", Information Systems, Vol. 37, No. 3, pp. 227-237, 2012, http://dx.doi. org/10.1016/j.is.2011.10.010.

[32] S. Wee, "Juggling toward ERP success: keep key success factors high", ERP News, February, available at: www.erpnews.com/erpnews/ erp904/ 02get.html, 2000.

[33] A. Scheer, and F. Habermann, "Enterprise resource planning: making ERP a success", Communications of the ACM, Vol. 43, No. 4, pp. 5761, 2000, http://dx.doi.org/10.1145/332051.332073.

[34] T.W. Ferratt, S. Ahire, and P. De, "Achieving success in large projects: implications from a study of ERP implementations", Interfaces, Vol. 36, No. 5, pp. 458-469, 2006.

[35] E.W.T. Ngai, C.C.H. Law, and F.K.T. Wat, "Examining the critical success factors in the adoption of enterprise resource planning", Computers in Industry, Vol. 59, No. 6, pp. 548-564, 2008, http://dx.doi.org/10.1016/j.compind.2007.12.001.

[36] C. Sheu, B. Chae, and C.-L. Yang, "National differences and ERP implementation: issues and challenges", Omega, Vol. 32, No. 5, pp. 361-371, 2004, http://dx.doi.org/10.1016/j.omega.2004.02.001.

[37] M. Tarafdar, and R.K. Roy, "Analyzing the adoption of enterprise resource planning systems in Indian organizations: a process framework", Journal of Global Information Technology Management, Vol. 6, No. 1, pp. 21-51, 2003, http://dx.doi.org/10.1080/1097198X.2 003.10856342 .

[38] C.K. Lee, H.H. Lee, and M. Kang, "Successful implementation of ERP systems in small businesses: a case study in Korea", Service Business, Vol. 2, No. 4, pp. 275-286, 2008, http://dx.doi.org/10.1007/ s11628-008-0045-3.

[39] E. Bernroider, and S. Koch, "ERP selection process in midsize and large organizations", Business Process Management Journal, Vol. 7, 
No. 3, pp. 251-257, 2001, http://dx.doi.org/10.1108/14637150110392 746.

[40] Y. Yusuf, A. Gunasekaranb, and M.S. Abthorpe, "Enterprise information systems project implementation: a case study of ERP in Rolls-Royce", International Journal of Production Economics, Vol. 87, pp. 251-266, 2004, , http://dx.doi.org/10.1016/j.ijpe.2003.10.004.

[41] P. Poba-Nzaou, L. Raymond, and B. Fabi, "Adoption and risk of ERP systems in manufacturing SMEs - a positivist case study", Business Process Management Journal, Vol. 14, No. 4, pp. 530-550, 2008, http://dx.doi.org/10.1108/14637150810888064.

[42] P. Liamputtong, Focus group methodology: Principle and practice, Sage Publications, London, UK, 2011.

[43] B.L. Berg, H. Lune, and H. Lune, Qualitative research methods for the social sciences, Pearson, MA: Boston, USA, 2004.

[44] R. Sharma, and P. Yetton, "The contingent effects of management support and task interdependence on successful information systems implementation”, MIS Quarterly, Vol. 27, No. 4, pp. 533-555, 2003.

[45] M. Al-Mashari, "A process change-oriented model for ERP application", International Journal of Human-computer Interaction, Vol. 16, No. 1, pp. 39-55, 2003, http://dx.doi.org/10.1207/S15327590I JHC1601 4.

[46] J.E. Umble, R.R. Haft, and M.M. Umble, "Enterprise resource planning: implementation procedures and critical success factors", European Journal of Operational Research, Vol. 146, No. 2, pp. 241257, 2003, http://dx.doi.org/10.1016/S0377-2217(02)00547-7.

[47] M. Al-Mashari, A. Al-Mudimigh, and M. Zairi, "Enterprise resource planning: a taxonomy of critical factors", European Journal of Operational Research, Vol. 146, No. 2, pp. 352-364, 2003, http://dx.doi.org/10.1016/S0377-2217(02)00554-4.

[48] M.T. Somers, and K.G. Nelson, "A taxonomy of players and activities across the ERP project life cycle", Information \& Management, Vol. 41, No. 3, pp. 257-278, 2004, http://dx.doi.org/ 10.1016/S0378-7206 (03)00023-5.

[49] S. Dezdar, and S. Ainin, "Examining ERP implementation success from a project environment perspective", Business Process Management Journal, Vol. 17, No. 6, pp. 919-939, 2011, http://dx.doi. org/10.1108/14637151111182693.

[50] L.C.S. Koh, M. Simpson, J. Padmore, N. Dimitriadis, and F. Misopoulos, "An exploratory study of enterprise resource planning adoption in Greek companies", Industrial Management \& Data Systems, Vol. 106, No. 7, pp. 1033-1059, 2006, http://dx.doi.org/10.1 $108 / 02635570610688913$.

[51] C.M. Jones, M. Cline, and S. Ryan, "Exploring knowledge sharing in ERP implementation: an organizational culture framework", Decision Support System, Vol. 41, No. 2, pp. 411-434, 2006, http://dx.doi.org/1 0.1016/j.dss.2004.06.017.

[52] L.S. Jarvenpaa, and S.D. Staples, "Exploring perceptions of organizational ownership of information and expertise", Journal of Management Information Systems, Vol. 18, No. 1, pp. 151-183, 2001, http://dx.doi.org/10.1080/07421222.2001.11045673.

[53] P.C. Ruppel, and J.S. Harrington, "Sharing knowledge through intranets: a study of organizational culture and intranet implementation", IEEE Transactions on Professional Communication, Vol. 44, No. 1, pp. 37-52, 2001, http://dx.doi.org/ 10.1109/47.911131.

[54] H. Liang, N. Saraf, Q. Hu, and Y. Xue, "Assimilation of enterprise systems: the effect of institutional pressures and the mediating role of top management", MIS Quarterly, Vol. 31, No. 1, pp. 59-87, 2007.

[55] E. Waarts, Y.M. van Everdingen, and J. van Hillegersberg, "The dynamics of factors affecting the adoption of innovations", The Journal of Product Innovation Management, Vol. 19, No. 6, pp. 412 423, 2002, , http://dx.doi.org/10.1111/1540-5885.1960412.

[56] M. Bradford, and S. Richtermeyer, "Realizing value in ERP", Cost Management, Vol. 16, No. 2, pp. 13-19, 2002

[57] G.T.E. Wang, C.-L.C. Lin, J.J. Jiang, and G. Klein, "Improving enterprise resource planning (ERP) fit to organizational process through knowledge transfer", International Journal of Information Management, Vol. 27, No. 3, pp. 200-212, 2007, http://dx.doi.org/ 10.1016/j.ijinfomgt.2007.02.002.

[58] S. El Sawah, A. Abd El Fattah Tharwat, and M. Hassan Rasmy, "A quantitative model to predict the Egyptian ERP implementation success index", Business Process Management Journal, Vol. 14, No. 3, pp. 288-306, 2008 http://dx.doi.org/10.1108/14637150810876643.
[59] G.T.E. Wang, and F.H.J. Chen, "Effects of internal support and consultant quality on the consulting process and ERP system quality", Decision Support Systems, Vol. 42, No. 2, pp. 1029-1041, 2006, http://dx.doi.org/10.1016/j.dss.2005.08.005.

[60] S.C.L. Koh, M. Simpson, J. Padmore, N. Dimitriadis, and F. Misopoulos, "An exploratory study of enterprise resource planning adoption in Greek companies", Industrial Management \& Data Systems, Vol. 10, No. 7, pp. 1033-1059, 2006, http://dx.doi.org/10.11 08/02635570610688913.

[61] S. Dezdar, and S. Ainin, "The influence of organizational factors on successful ERP implementation", Management Decision, Vol. 49, No. 6 pp. 911-926, 2011, http://dx.doi.org/10.1108/00251741111143603.

[62] J. Bradley, "Management based critical success factors in the implementation of Enterprise Resource Planning systems", International Journal of Accounting Information systems, Vol. 9, No. 3, pp. 175-200, 2008, http://dx.doi.org/10.1016/j.accinf.2008.04.001.

[63] F.H. Nah, K.M. Zuckweiler, and L.S. Lau, "ERP Implementation: chief information officers' perceptions of critical success factors", International Journal of Human-Computer Interaction, Vol. 16, No. 1, pp. 5-22, 2003, http://dx.doi.org/ 10.1207/S15327590IJHC1601 2.

[64] E.J. Ettlie, J.V. Perotti, A.D. Joseph, and J.M. Cotteleer, "Strategic predictors of successful enterprise systems deployment", International Journal of Operations \& Production Management, Vol. 25, No. 10, pp. 953-972, 2005, http://dx.doi.org/10.1108/01443570510619473.

[65] A. Madapusi, and D. D'Souza, "The influence of ERP system implementation on the operational performance of an organizational", International Journal of Information Management, Vol. 32, No. 1, pp. 24-34, 2012, http://dx.doi.org/10.1016/j.ijinfomgt.2011.06.004.

[66] T.M. Yeh, C.C. Yang, and W.T. Lin, "Service quality and ERP implementation: a conceptual and empirical study of semiconductorrelated industries in Taiwan", Computers in Industry, Vol. 58, No. 8-9, pp. 844-854, 2007, http://dx.doi.org/ 10.1016/j.compind.2007.03.002.

[67] A.V. Mabert, A. Soni, and A.M. Venkataramanan, "Enterprise resource planning: measuring value", Production and Inventory Management Journal, Vol. 42, No. 3-4, pp. 46-51, 2001.

[68] H.C.C. Law, and T.W.E. Ngai, "ERP systems adoption: an exploratory study of the organizational factors and impacts of ERP success", Information \& Management, Vol. 44, , pp. 418-432, 2007, http://dx. doi.org/ 10.1016/j.im.2007.03.004.

[69] M. Gupta, and A. Kohli, "Enterprise resource planning systems and its implications for operations function", Technovation, Vol. 26, No. 5-6, pp. 687-696, 2006, http://dx.doi.org/10.1016/j.technovation.2004.10. 005 .

[70] K. Laframboise, and F. Reyes), "Gaining competitive advantage from integrating enterprise resource planning and total quality management", Journal of Supply Chain Management, Vol. 41, No. 3, pp. 49-64, 2005, http://dx.doi.org/ 10.1111/j.1055-6001.2005.0410300 5.x

[71] F. Hair, R. Anderson, R. Tatham, and W. Black, Multivariate Data Analysis with Readings, London: Prentice-Hall International, 1995.

[72] R.E. Schumacker, and R.G. Lomax, A Beginner's Guide to Structural Equation Modeling, New York: Routledge Academic, 2010.

[73] E.K. Kelloway, Using LISREL for Structural Equation Modeling: A Researcher's Guide, Thousand Oaks, CA: Sage, 1998.

[74] B.M. Byrne, Structural equation modeling with AMOS: Basic concepts, applications, and programming. UK: Routledge, 2013.

[75] E. Ziemba and I. Kolasa, "Risk factors framework for information systems projects in public organizations-insight from Poland", 2015 Federated Conference on Computer Science and Information Systems (FedCSIS), IEEE, pp. 1575-1583, 2015, http://dx.doi.org/ 10.15439/2 $015 \mathrm{~F} 110$.

[76] P. Soja, "Understanding determinants of enterprise system adoption success: Lessons learned from full-scope projects in manufacturing companies", Production Planning \& Control, Vol. 21, No. 8, pp. 736750, 2010, http://dx.doi.org/ 10.1080/09537281003601597. 